\title{
Hyperoxaluria Type I: Therapeutic Effects of Pyridoxine Hydrochloride and Inheritance Patterns of the Disease in a Family
}

\author{
SHOJI YANO, MAKOTO YOSHINO, ATSUSHI NISHIYORI, MITSUYOSHI NAKAO, \\ TORU MATSUMOTO, YUHEI ITO, FUMIO YAMASHITA, AKIHIKO SHIMADA* \\ AND TAKAHIRO INOKUCHI**
}

Departments of Pediatrics and Child Health, Urology* and Biomedical Mass Spectrometry Laboratory**, Kurume University School of Medicine, Kurume, 830 Japan

Received for publication July 18, 1988

\begin{abstract}
Summary: The cases of two patients with primary hyperoxaluria type I, aged five years and two years, born to consanguineous parents are described. These patients have been treated with oral pyridoxine hydrochloride at a dose of $200 \mathrm{mg} / 24 \mathrm{hr}$ without evidence that this regimen has decreased urinary oxalate excretion. Studies of oxalate excretion in the family members yielded results consistent with either autosomal dominant inheritance, with variable expressivity, or with autosomal recessive character.
\end{abstract}

Key words: urolithiasis in infancy-primary hyperoxaluria type I-pyridoxine - mode of inheritance - glycolate

\section{Introduction}

Primary hyperoxaluria has been classified into two specific entities; type I and type II (Williams and Smith, 1983). Type I disease is caused by a defect in either soluble 2-oxoglutarate: glyoxylate carboligase (Koch et al. 1967) or peroxisomal alanine: glyoxylate aminotransferase (Danpure and Jennings, 1986; Danpure et al. 1987). While in type II disease, a deficiency of D-glyceric dehydrogenase has been demonstrated (Williams and Smith, 1983). These diseases often present with urolithiasis and hematuria in infancy and progress to chronic renal failure in later stages. In type I disease, synthesis of not only oxalate but glycolate is enhanced (Fig. 1), and the excessive oxalate syn- thesis may eventually result in deposition of calcium oxalate in the kidney and extrarenal tissues, presenting as a condition termed oxalosis.

Pyridoxine in large doses has been administered to several patients with this disease, resulting in significant decreases in oxalate excretion in some of the patients (Gibbs and Watts, 1970; Gill and Rose, 1986; Morgan et al. 1987). This pyridoxine-induced decrease in oxalate excretion is presumably effected through the depletion of the glyoxylate pool by conversion to glycine. Glyoxylate undergoes transamination to glycine with alanine (Danpure and Jennings, 1986) in a reaction which requires pyridoxalphosphate as a cofactor (Fig. 1). It is not known, however, whether or not pyridoxine can pre-

Reprint requests to: Dr. S. Yano, Department of Pediatrics and Child Health, Kurume University School of Medicine, Kurume, 830 Japan 


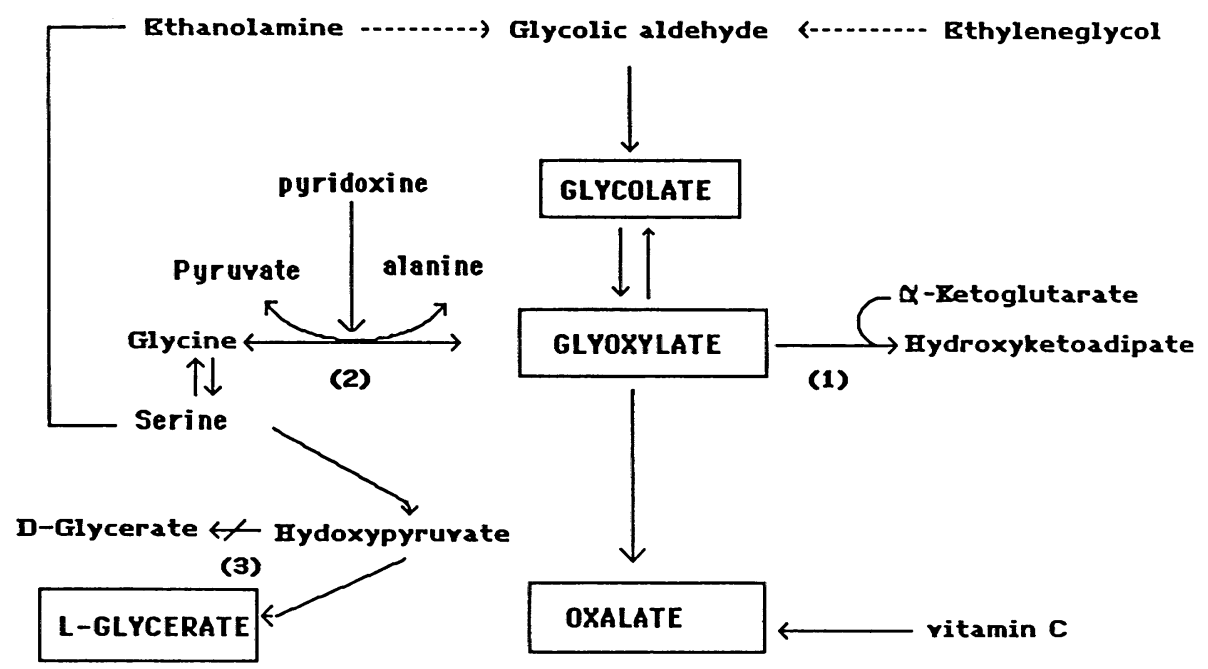

Fig. 1. Metabolic pathway of glyoxylate.

Enzymes involved: (1) 2-oxo-glutarate: glyoxylate carboligase, (2) alanine: glyoxylate aminotransferase, (3) D-glyceric dehydrogenase.

vent or retard the progression of the renal disease.

Type I disease is generally thought to be inherited in an autosomal recessive manner (Hockaday et al. 1964), although in some pedigrees, dominant inheritance has been suggested (De Toni and Durand, 1959; Shepard et al. 1960).

We describe in this report the effects of pyridoxine on oxalate excretion in two siblings with type I hyperoxaluria, and present results of a genetic study in this family.

\section{Methods}

Oxalalate in urine was determined by gas chromatography with malonic acid as an internal standard (Yachiku and Kamidate, 1985). The other organic acids in urine, including glycolate and glycerate, were extracted and derivatized as previously described (Tanaka et al. 1980) and analyzed by gas chromatography-mass spectrometry (GC/MS).

\section{Case Reports}

\section{Patient 1.}

The proband D.H. (87-2350), a five year and four month-old boy, was referred to Kurume University Medical Center because of nephrolithiasis. $\mathrm{He}$ was born to consanguineous parents after an uneventful pregnancy and delivery at 38 weeks of gestation. The birth weight was $3.030 \mathrm{~g}$. $\mathrm{He}$ has achieved developmental milestones normally. He has had several episodes of fever of unknown cause in early infancy. Because he suddenly became unable to void at the age of five years and four months, he was brought to a local clinic, where multiple radiopaque urinary caliculi were found. He was referred to us for further evaluation of the urolithiasis four months later.

Other than shortness of stature (height at the 3 percentile level), there were no positive findings upon physical examination at admission.

Urinalysis was negative for both protein and glucose, and the sediment con- 


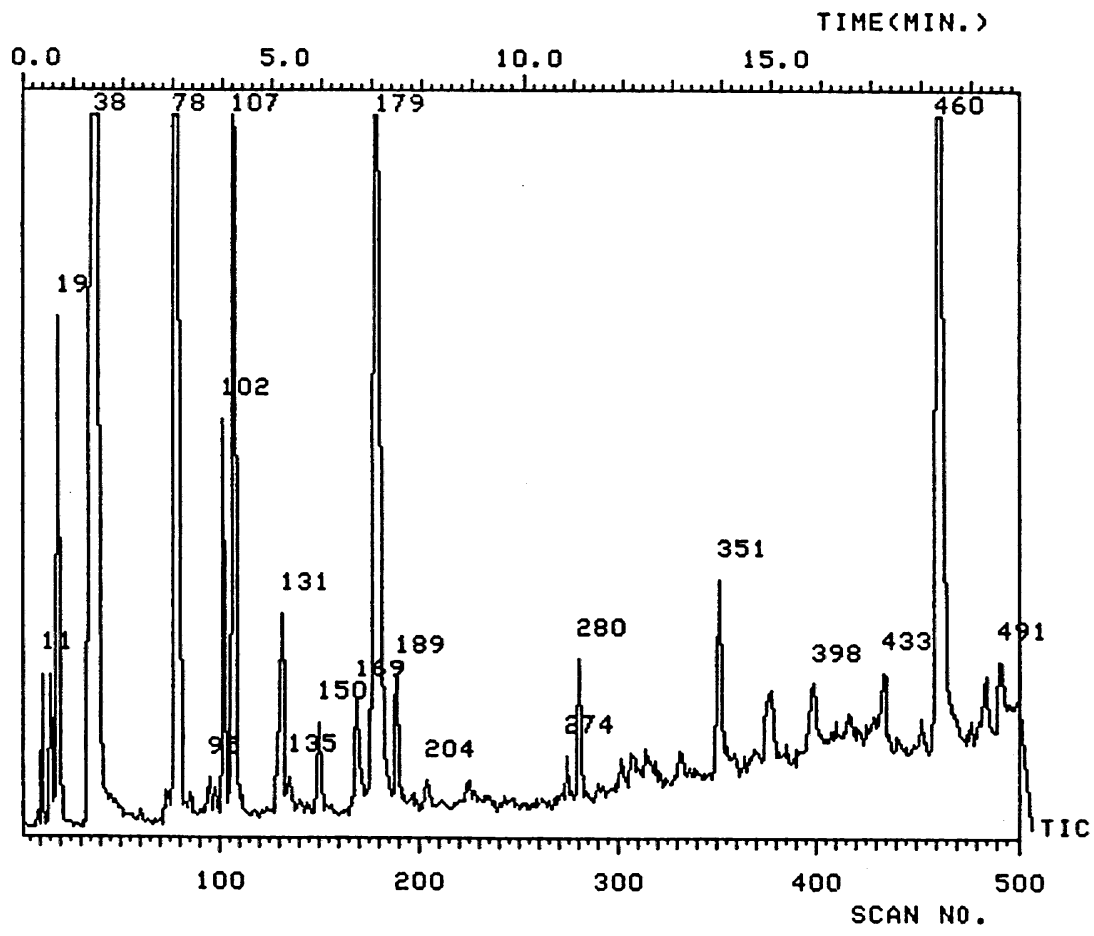

(A)
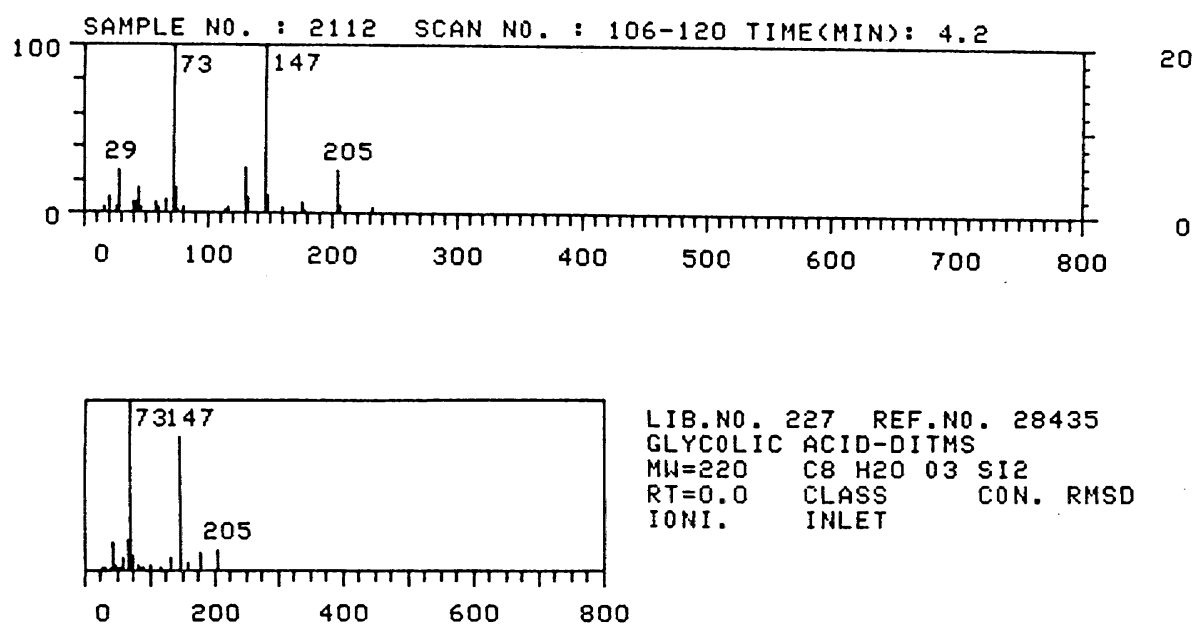

LIB.NO. 227 REF.NO. 28435

GLYCOLIC ACID-DITMS

$M W=220 \quad C 8 \mathrm{H}_{20} 03 \mathrm{SII}$

RT $=0.0$ CLASS CON. RMSD

IONI. INLET

(B)

Fig. 2. (A) Total ion current chromatogram, (B) top, mass spectrum of sample chromatogram peak \#107, and (B) bottom, mass spectrum of authentic ditrimethylsilylglyoxylate. 
tained 0 to 20 erythrocytes, and numerous leukocytes per high-power field. Concentrations in serum of creatinine and urea nitrogen were $0.8 \mathrm{mg} / \mathrm{dl}$ and $15.0 \mathrm{mg} / \mathrm{dl}$, respectively. Renal function studies revealed the following: creatinine clearance $49 \mathrm{ml} / \mathrm{min} / 1.73 \mathrm{~m}^{2}$, excretion of phenolsulfonphthalein $2.1 \%$ at $15 \mathrm{~min}$ and $20.5 \%$ at $120 \mathrm{~min}$, fractional excretion of sodium 0.62 to $2.18 \%$, and tubular reabsorption of phosphate 65 to $73 \%$. There were minimal increases in urine cystine, arginine, ornithine, methionine and proline. Concentration of $\beta_{2}$-microglobulin was $3220 \mu \mathrm{g} / 1$ in urine. Liver function tests, blood counts, and blood gas values were within respective normal ranges. The plain abdominal $\mathrm{x}$-ray disclosed multiple clusters of radiopaque lesions consistent with urolithiasis. Bone age was at the level of two years of chronological age. Analysis of a passed stone revealed that it consisted exclusively of calcium oxalate. Excretion of oxalate in urine ranged from 78 to $89 \mathrm{mg} / 24 \mathrm{hr}$, or from 204 to $232 \mathrm{mg} / 24 \mathrm{hr} / 1.73 \mathrm{~m}^{2}$, whereas the normal range for adults is 10 to $45 \mathrm{mg}$ $/ 24 \mathrm{hr}$ (Yachiku and Kamidate, 1985). Massive excretion in urine of glycolate was found, but L-glycerate was undetectable (Figs. 2A and 2B). This profile of urinary organic acids led us to the diagnosis of primary hyperoxaluria type I.

\section{Patient 2.}

A younger brother of the proband, T. H. (88-80), who has been growing normally without any clinical signs, was found to have an elevated level of urinary oxalate and urolithiasis at the age of two years and two months, while the family was being surveyed.

Physical examination revealed no abnormality. Urinalysis showed 7 to 8 erythrocytes and numerous leukocytes per high-power field. Serum levels of creatinine and urea nitrogen were $0.4 \mathrm{mg} / \mathrm{dl}$ and $8.9 \mathrm{mg} / \mathrm{dl}$, respectively. Serum electrolytes and blood gas values were within respective normal ranges. $\mathrm{X}$-ray of the abdomen revealed multiple calcified lesions. Amounts of oxalate excreted in urine ranged from 39 to $101 \mathrm{mg} /$ day or from 129 to $336 \mathrm{mg} / 24 \mathrm{hr} / 1.73 \mathrm{~m}^{2}$.

\section{Family Study}

The proband was born of consanguineous parents (Fig. 3). Studies of family members revealed that father, paternal grandfather, and sister of the proband were hyperexcretors of oxalate. Although

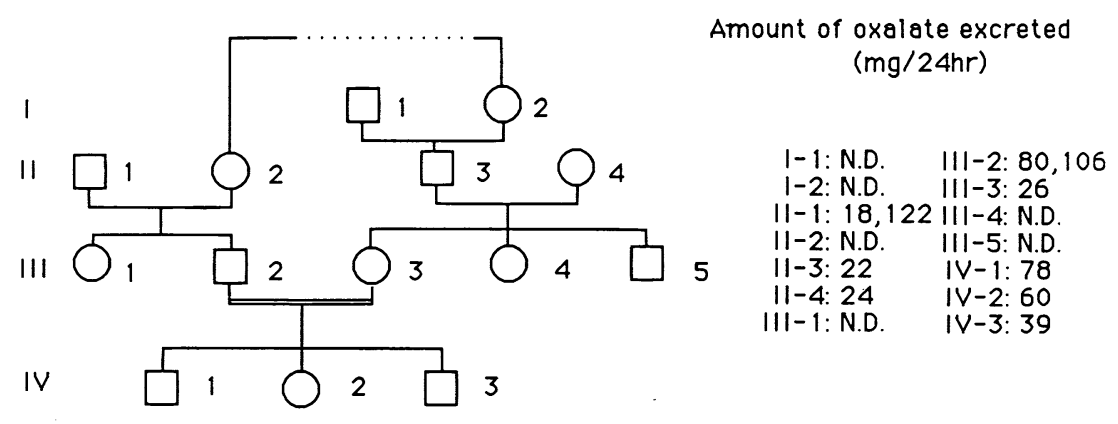

Fig. 3. Pedigree chart.

Note relation of maternal great-grandmother and paternal grandmother (paternal grand mother (II-2) and maternal great-grandmother are cousins once removed). 


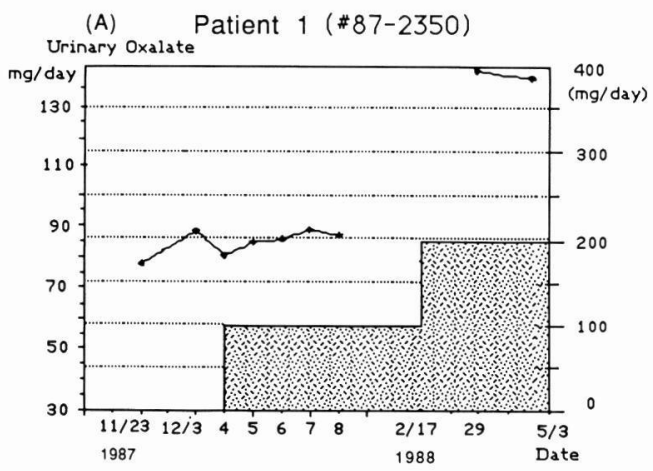

(A)

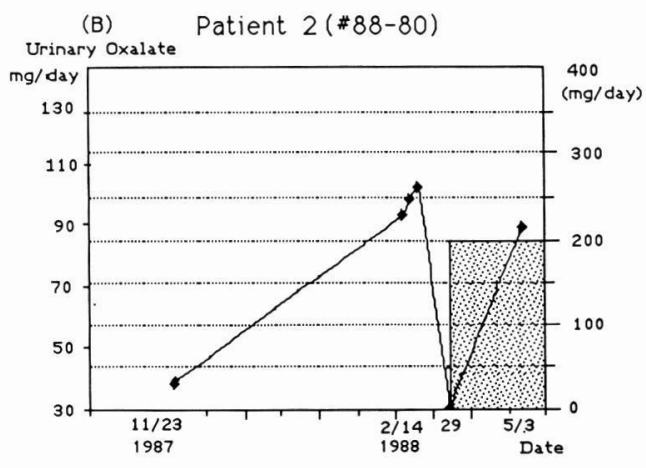

(B)

Fig. 4. Effects of pyridoxine hydrochloride on oxalate excretion in the proband (A) and the younger brother (B). Lines indicate oxalate levels, and the stippled columns represent dose of pyridoxine hydrochloride.

normal ranges of oxalate excretion for children have not been clearly established, the excretion of oxalate corrected for body surface area seems to be comparable to that in adults (Gibbs and Watts, 1969). The sister of the proband was therefore interpreted to be a hyperexcretor.

\section{Responsiveness to Pyridoxine hydrochloride}

We evaluated possible effectiveness of pyridoxine hydrochloride in the prodand and the younger brother. The proband received $100 \mathrm{mg} /$ day of pyridoxine hydrochloride for the initial three months of treatment and has been receiving $200 \mathrm{mg}$ /day subsequently without significant change in oxalate excretion (Fig. $4 \mathrm{~A}$ ). $\mathrm{Pa}$ tient 2 has been given $200 \mathrm{mg}$ /day of the same preparation. Although oxalate excretion decreased transiently immediately after the introduction of pyridoxine therapy, it rose again within two months to the pre-treatment level (Fig. 4B).

\section{Discussion}

Hyperoxaluria type I often presents with hematuria or urolithiasis in infancy. This disease often progresses to renal failure in adulthood in the majority of patients, but renal failure may become overt at an earlier stage. The major therapeutic goal in combatting this disease is therefore the prevention or amelioration of renal failure.

Pyridoxine in large doses has been tried for this purpose (Gibbs and Watts, 1970; Gill and Rose, 1986; Morgan et al. 1987). Glyoxylate, the immediate precursor to oxalate, is converted to glycine mainly by alanine: glyoxylate aminotransferase, a pyridoxine dependent enzyme (Fig. 1), and deficiency of this enzyme has been demonstrated in some of the patients with hyperoxaluria type I (Dunpure and Jennings, 1986; Dunpure et al. 1987). Enhancement of the activity of this enzyme by pyridoxine would increase glyoxylate conversion to glycine, resulting in a diversion in the glyoxylate pool which is otherwise converted to oxalate.

Reduction of oxalate excretion by pyridoxine has been demonstrated in a number of patients, but effect of the vitamin on overall clinical status has not been documented in such patients. Failure to improve clinical status by pyridoxine therapy in the majority of these patients may be partly due to the fact that treatment was started after renal damage had developed. 
In the proband of the present family, pyridoxine at a dose of $200 \mathrm{mg} /$ day did not appear to decrease oxalate excretion. In the younger brother there was a transient decline in oxalate excretion immediately following the start of pyridoxine administration, followed by an increase. Follow up for a longer period and with larger doses of the vitamin appears to be necessary to evaluate efficacy of this regimen in our patients.

Primary oxaluria type $I$ is presumed to be inherited in an autosomal recessive manner in the majority of reported pedigrees (Hockaday et al. 1964; Williams and Smith, 1983). There are, however, some exceptional pedigrees in which the trait is transmitted in a mode consistent with autosomal dominance (De Toni and Durand, 1959; Shepard et al. 1960). In the family of our patients (Fig. 3), two siblings of the proband are hyperexcretors of oxalate, and in addition, the younger brother exhibited radiopaque lesions consistent with nephrolithiasis.

In previously studied families in which autosomal recessive mode of inheritance of this disease is suspected, urinary oxalate excretion has been almost invariably normal in parents of patients (Hockaday et al. 1964). In contrast to this, father and paternal grandfather of the proband in this case excreted oxalate in abnormally increased amounts but in smaller amounts than those generally observed in patients (Hockaday et al. 1964).

The mother's oxalate excretion was normal. These observations imply that in this particular family the disease is transmitted as an autosomal dominant character with a variable expressivity. However, in view of the fact that paternal grandmother (Fig. 3, II-2) and maternal great grandmother (Fig. 3, I-2) of the proband were related, it is also possible that this disease is inherited autosomal recessively, the parents of the proband being heterozygous, and the offspring, at least the proband and the younger brother, homozygous for this disease trait. In this situation, the moderate hyperoxaluria in father and paternal grandfather may be explicable as the product of heterozygous effect.

This work was partly supported by the grant from the Ministry of Health and Welfare of Japan.

\section{References}

Danpure, C. J. and Jennings, P.R. (1986). Peroxisomal alanine: glyoxylate aminotransferase deficiency in primary hyperoxaluria type I. FEBS Letters 201, 20-24.

Danpure, C. J., Jennings, P.R. and Watts, R. W.E. (1987). Enzymological diagnosis of primary hyperoxaluria type I by glyoxylate aminotransferase activity. Lancet, i, 289-291.

De Toni, G. and Durand, P. (1959). Observations on two opposite clinical situations: renal acidosis and alkalosis. Ann. Paediat. 193, 257278.

GibBs, D. A. and Watts, R.W.E. (1969). The variation of urinary oxalate excretion with age. J. Lab. and Clin. Med. 73, 901-908.

GiBbs, D. and Watrs, R. W.E. (1970). The action of pyridoxine in primary hyperoxaluria. Clin. Sci. 38, 277-286.

GiLl, H.S. and Rose, G. A. (1986). Mild metabolic hyperoxaluria and its response to pyridoxine. Urol. Int. 41, 393-396.

Hockaday, T.D.R., Clayton, J.E., Frederick, E.W. and Smith, L. H., Jr. (1964). Primary hyperoxaluria. Medicine 43, 315-345.

Koch, J., Stokstad, E.L.R., Williams, H.E. and Sмiтh, L. H., Jr. (1967). Deficiency of 2-oxoglutarate: glyoxylate carboligase activity in primary hyperoxaluria. Proc. Natl. Acad. Sci. USA. 57, 1123-1129.

Morgan, S. H., Purkiss, P., Watts, R.W.E. and Mansell, M. A. (1987). Oxalate dymanics in chronic renal failure comparison with normal subjects and patients with primary hyperoxaluria. Nephron 46, 253-257.

Shepard, T. H. II., Lee, L. W. and Krebs, E.G. (1960). Primary hyperoxaluria. II. Genetic studies in a family. Pediatrics 25, 869-871.

Tanaka, K., Hine, D. G.; West-Dull, A. and Lynn, T.B. (1980). Gas-chromatographic method of 
analysis for urinary organic acids. I. retention indices of 155 metabolically important compounds. Clin. Chem. 26, 1839-1846.

Williams, H.E. and Smith, L. H. (1983). Primary hyperoxaluria. In The Metabolic Basis of Inherited Disease, eds. Stanbury, J. B., Wyngaarden, J. B., Fredrickson, D. S., Goldstein, J.L. and Brown, M.S., edn. 5th, pp. 204-228, New York: McGraw-Hill, Inc.

Yachiku, S. and Kamidate, T. (1985). The determination of urinary oxalate by gas-chromatography. Jpn. J. Urol. 76, 502-507. (in Japanese) 